\title{
JBIR-54, a new 4-pyridinone derivative isolated from Penicillium daleae Zaleski fE50
}

\author{
Akira Mukai $^{1}$, Aya Nagai $^{1}$, Shigeki Inaba ${ }^{2}$, Motoki Takagi ${ }^{1}$ and Kazuo Shin-ya ${ }^{3}$
}

The Journal of Antibiotics (2009) 62, 705-706; doi:10.1038/ja.2009.101; published online 23 October 2009

Keywords: JBIR-54; Penicillium daleae; pyridinone

Penicillium is a versatile ascomyceteous fungi. It causes opportunistic infections and putrefaction of foods. Penicillium species are known to produce more than 900 documented bioactive compounds. ${ }^{1}$ Furthermore, important pharmaceutical agents, namely, penicillins and compactin, have been isolated from Penicillium spp. We have reported that this fungus also produces valuable secondary metabolites, such as JBIR-12, ${ }^{2}$ JBIR-27 ${ }^{3}$ and JBIR-28. ${ }^{3}$ Therefore, we further screened for novel secondary metabolites from culture broths of Penicillium species. In this paper, we report the fermentation, isolation and structural determination of a new secondary metabolite, JBIR-54 (1), in addition to the taxonomy of the producing microorganism.

The Penicillium daleae Zaleski fE50 strain that produced $\mathbf{1}$ was isolated by the sodium dodecyl sulfate-yeast extract method ${ }^{4}$ from a soil sample collected in Fukui Prefecture, Japan. The soil was treated with a solution containing $6 \%$ bacto-yeast extract (BD Biosciences, San Jose, CA, USA) and $0.05 \%$ sodium dodecyl sulfate at $40{ }^{\circ} \mathrm{C}$ for $20 \mathrm{~min}$. The solution was diluted with water, plated on potato dextrose agar plates, and incubated at $27^{\circ} \mathrm{C}$ for a few weeks. Individual fungal colonies that appeared on the plate were transferred to potato dextrose agar slants and individual strains were maintained. The fE50 strain was identified by sequence analysis of the ribosomal DNA ITS region, and its microscopic features were observed by using a Zeiss Axioplan 2 imaging system (Carl Zeiss, Oberkochen, Germany). Sequence and morphological analysis revealed that the fE50 strain was $99.8 \%$ similar to the $P$. daleae strain NRRL 922. Thus, the strain was identified as $P$. daleae Zaleski.

The seed medium was potato dextrose broth $\left(24 \mathrm{gl}^{-1}\right.$ potato dextrose; $\mathrm{BD}$ Biosciences). The production medium containing $3 \mathrm{~g}$ brown rice (Hitomebore, Miyagi, Japan), $6 \mathrm{mg}$ bacto-yeast extract (BD

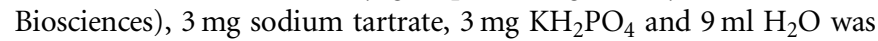
dispensed in 100-ml Erlenmeyer flasks. The fE50 strain was cultivated in 50 - $\mathrm{ml}$ test tubes containing $15 \mathrm{ml}$ of seed medium. The test tubes were shaken on a reciprocal shaker ( 355 r.p.m.) at $27^{\circ} \mathrm{C}$ for 3 days. Aliquots $(1 \mathrm{ml})$ of the culture were transferred to $100-\mathrm{ml}$ Erlenmeyer flasks containing the production medium and incubated in static culture at $27^{\circ} \mathrm{C}$ for 14 days.

The culture of fE50 strain $(100-\mathrm{ml}$ Erlenmeyer flasks $\times 20)$ was extracted with $80 \%$ aqueous $\mathrm{Me}_{2} \mathrm{CO}$. The extract was evaporated in vacuo, and the residual aqueous concentrate was extracted with EtOAc $(100 \mathrm{ml} \times 3)$. After drying over $\mathrm{Na}_{2} \mathrm{SO}_{4}$, the organic layer was evaporated to dryness. The dried residue $(20.4 \mathrm{mg})$ was applied to a normal-phase medium-pressure liquid chromatography column (Purif-Pack SI-60; Moritex, Tokyo, Japan) and eluted with a chloroform- $\mathrm{MeOH}$ gradient $(0-50 \% \mathrm{MeOH})$. The main fraction $(0.98 \mathrm{mg})$ was finally separated by preparative HPLC using an L-column2 ODS (20 i.d. $\times 150 \mathrm{~mm}$; Chemical Evaluation Research Institute, Tokyo, Japan) with $55 \%$ aqueous $\mathrm{MeOH}$ (flow rate, $10 \mathrm{ml} \mathrm{min}^{-1}$, UV detection: $254 \mathrm{~nm})$ to obtain the new compound $1(0.48 \mathrm{mg}$; retention time, $14 \mathrm{~min}$ ).

Compound 1 was obtained as a white powder $\left([\alpha]_{\mathrm{D}}{ }^{25}=-22.2\right.$; $c=0.1$ in $\mathrm{MeOH}$; UV (MeOH) $\lambda_{\max }(\varepsilon): 223$ (15000), $316 \mathrm{~nm}$ (9800), and its IR spectrum showed the characteristic absorptions of the carbonyl group $\left(v_{\max }, 1669 \mathrm{~cm}^{-1}\right)$. The HR electron spray ionizationMS of 1 produced the $(\mathrm{M}+\mathrm{H})^{+}$ion at $m / z 236.1669$ consistent with the molecular formula of $\mathrm{C}_{14} \mathrm{H}_{22} \mathrm{NO}_{2}$ (calculated value for $\mathrm{C}_{14} \mathrm{H}_{22} \mathrm{NO}_{2}, 236.1651$ ).

The structure of 1 was elucidated by a series of NMR techniques, such as constant time heteronuclear multibond correlation (CT-HMBC) $)^{5}$ and double-quantum filtered (DQF)-COSY. The direct $\mathrm{C}-\mathrm{H}$ connectivity was established by heteronuclear single quantum coherence (see Table 1). In the DQF spectrum, the sequence from a methyl proton $1-\mathrm{H}_{3}\left(\delta_{\mathrm{H}} 1.01\right)$ to an olefinic proton $6-\mathrm{H}\left(\delta_{\mathrm{H}} 5.66\right)$

${ }^{1}$ Biomedicinal Information Research Center (BIRC), Japan Biological Informatics Consortium (JBIC), Tokyo, Japan; ${ }^{2}$ NITE Biotechnology Development Center (NBDC), Department of Biotechnology, National Institute of Technology and Evaluation (NITE), Chiba, Japan and ${ }^{3}$ Biomedicinal Information Research Center (BIRC), National Institute of Advanced Industrial Science and Technology (AIST), Tokyo, Japan

Correspondence: Dr M Takagi, Biomedicinal Information Research Center (BIRC), Japan Biological Informatics Consortium (JBIC), 2-42 Aomi, Koto-ku, Tokyo 135-0064, Japan. E-mail: motoki-takagi@aist.go.jp or Dr K Shin-ya, Biomedicinal Information Research Center (BIRC), National Institute of Advanced Industrial Science and Technology (AIST), 2-42 Aomi, Koto-ku, Tokyo 135-0064, Japan.

E-mail: k-shinya@aist.go.jp

Received 5 August 2009; revised 29 September 2009; accepted 1 October 2009; published online 23 October 2009 
Table $1{ }^{1} \mathrm{H}$ - and ${ }^{13} \mathrm{C}-\mathrm{NMR}$ data of JBIR-54 (1)

\begin{tabular}{lrl}
\hline Position & \multicolumn{1}{c}{$\delta_{C}$} & \multicolumn{1}{c}{$\delta_{H}(\mathrm{~J}$ in Hz) } \\
\hline 1 & 13.6 & $1.01, \mathrm{t}(7.5,7.5)$ \\
2 & 26.0 & $2.12, \mathrm{~m}$ \\
3 & 139.2 & $5.81, \mathrm{~m}$ \\
4 & 128.1 & $6.01, \mathrm{dd}(10,15)$ \\
5 & 130.5 & $6.28, \mathrm{dd}(10,15)$ \\
6 & 133.3 & $5.66, \mathrm{~d}(15)$ \\
7 & 73.4 & \\
$7-\mathrm{OH}$ & & 1.90 \\
8 & 28.1 & $1.54, \mathrm{~s}$ \\
9 & 168.6 & \\
10 & 95.4 & $4.97, \mathrm{~s}$ \\
11 & 193.2 & \\
12 & 43.3 & $2.26, \mathrm{dd}(6,12)$ \\
13 & & $2.35, \mathrm{dd}(6,12)$ \\
14 & 49.0 & $3.76, \mathrm{~m}$ \\
$14-\mathrm{NH}$ & 20.5 & $1.33, \mathrm{~d}(6.5)$ \\
\hline
\end{tabular}

The ${ }^{13} \mathrm{C}(125 \mathrm{~Hz})$ and ${ }^{1} \mathrm{H}(500 \mathrm{~Hz})$ NMR spectra were obtained using a Varian NMR system $500 \mathrm{NB} C \mathrm{CL}$ (Palo Alto, $\mathrm{CA}, \mathrm{USA}$ ) in $\mathrm{CDCl}_{3}$, and the solvent peak was used as an internal standard ( $\delta_{\mathrm{C}} 77.0$ p.p.m.; $\delta_{\mathrm{H}} 7.26$ p.p.m.).

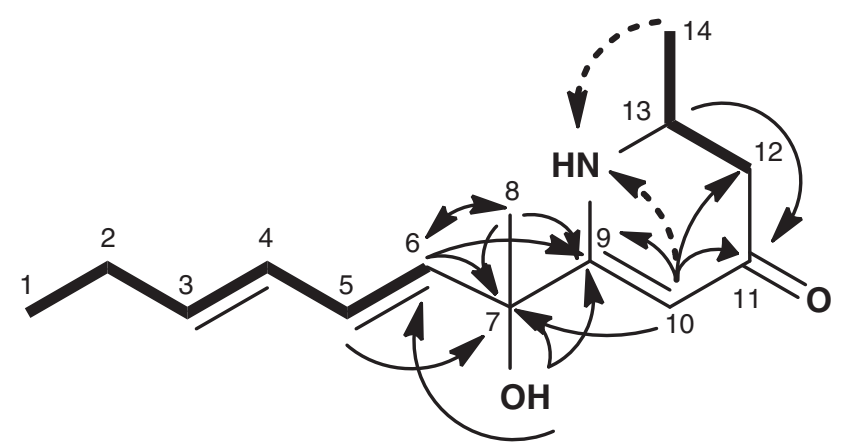

Figure 1 Structure of 1 , and ${ }^{1} \mathrm{H}-{ }^{1} \mathrm{H}$ (bold lines), main ${ }^{1} \mathrm{H}-{ }^{13} \mathrm{C}$ (solid arrows) and ${ }^{1} \mathrm{H}-{ }^{15} \mathrm{~N}$ (dotted arrow) correlations in 2D NMR.

through a methylene proton $2-\mathrm{H}_{2}\left(\delta_{\mathrm{H}} 2.12\right)$, an olefinic proton $3-\mathrm{H}$ $\left(\delta_{\mathrm{H}} 5.81\right)$, an olefinic proton $4-\mathrm{H}\left(\delta_{\mathrm{H}} 6.01\right)$ and an olefinic proton $5-\mathrm{H}$ $\left(\delta_{\mathrm{H}} 6.28\right)$ was observed as shown in Figure 1. Another spin coupling system was detected from the methylene proton $12-\mathrm{H}_{2}\left(\delta_{\mathrm{H}} 2.26,2.35\right)$ to the methyl proton $14-\mathrm{H}_{3}\left(\delta_{\mathrm{H}} 1.33\right)$ through the methine proton $13-\mathrm{H}\left(\delta_{\mathrm{H}} 3.76\right)$. A 2,3-dihydropyridin-4-one moiety was identified by the following correlation. Long-range couplings from the olefinic proton $10-\mathrm{H}\left(\delta_{\mathrm{H}} 4.97\right)$ to the carbonyl carbon C-11 $\left(\delta_{\mathrm{c}} 193.2\right)$ and methylene carbon C-12 $\left(\delta_{\mathrm{c}} 43.3\right)$, as well as from the methine proton $13-\mathrm{H}$ to $\mathrm{C}-11$ were observed by CT-HMBC. Moreover, ${ }^{1} \mathrm{H}-{ }^{15} \mathrm{~N}$ longrange couplings from $10-\mathrm{H}$ and $14-\mathrm{H}_{3}$ to an amine nitrogen atom 9-NH were observed. On the basis of the ${ }^{13} \mathrm{C}$ chemical shift at C-13 $\left(\delta_{\mathrm{c}} 49.0\right)$, this nitrogen atom was confirmed to be substituted at the $\mathrm{C}-13$ position. Thus, these members form a cyclic structure, which is 2-methyl-2,3-dihydropyridin-4-one (Figure 1). The long-range couplings from the methyl proton $8-\mathrm{H}_{3}\left(\delta_{\mathrm{H}} 1.54\right)$ to the olefinic carbon C-6, quaternary carbon C-7 $\left(\delta_{\mathrm{c}} 73.4\right)$ and olefinic quaternary carbon C-9 $\left(\delta_{\mathrm{c}} 168.6\right)$, which in turn is long-range coupled from the olefinic proton $10-\mathrm{H}$, as well as from the hydroxyl proton $7-\mathrm{OH}\left(\delta_{\mathrm{H}} 1.90\right)$ to the olefinic carbon C-6 $\left(\delta_{\mathrm{c}} 133.3\right)$, quaternary carbon C-7 and olefinic quaternary carbon C-9 revealed that the side chain moiety was substituted at the C-9 position. The coupling constants between $3-\mathrm{H}$ and $4-\mathrm{H}(J=15 \mathrm{~Hz})$, and $5-\mathrm{H}$ and $6-\mathrm{H}(J=15 \mathrm{~Hz})$ indicated that the configurations at $\mathrm{C}-3$ and $\mathrm{C}-5$ are trans. Thus, the structure of $\mathbf{1}$ was determined as shown in Figure 1. Streptazone D, a derivative of $\mathbf{1}$, is a known secondary metabolite of Streptomyces sp. ${ }^{6}$ To the best of our knowledge, this is first report of streptazone $\mathrm{D}$ analogs from fungi.

The 2-pyridinone analogs are reported to be non-nucleoside reverse-transcriptase inhibitors that can be used as anti-HIV agents. ${ }^{7}$ The antimicrobial activities of 2- and 4-pyridinone analogs have also been studied. ${ }^{8,9}$ Therefore, we attempted to investigate the cytotoxic and antimicrobial activities of $\mathbf{1}$. The results showed that $\mathbf{1}$ did not exhibit cytotoxic activity against several cancer cell lines or antibacterial activity against Micrococcus luteus and Escherichia coli.

\section{ACKNOWLEDGEMENTS}

This work was supported by a grant from the New Energy and Industrial Technology Department Organization (NEDO) of Japan.

1 Bérdy, J. Bioactive microbial metabolites. J. Antibiot. 58, 1-26 (2005).

2 Izumikawa, M., Nagai, A., Doi, T., Takagi, M. \& Shin-Ya, K. JBIR-12, a novel antioxidative agent from Penicillium sp. NBRC 103941. J. Antibiot. 62, 177-180 (2009).

3 Motohashi, K. et al. New sesquiterpenes, JBIR-27 and -28, isolated from a tunicatederived fungus, Penicillium sp. SS080624SCf1. J. Antibiot. 62, 247-250 (2009).

4 Hayakawa, M. \& Nonomura, H. A new method for the intensive isolation of actinomycetes from soil. Actinomycetologica 3, 95-104 (1989).

5 Furihata, K. \& Seto, H. Constant time HMBC (CT-HMBC), a new HMBC technique useful for improving separation of cross peaks. Tetrahedron Lett. 39, 7337-7340 (1998).

6 Puder, C., Krastel, P. \& Zeeck, A. Streptazones A, B,$B_{2}$, C, and D: new piperidine alkaloids from streptomycetes. J. Nat. Prod. 63, 1258-1260 (2000).

7 Tucker, T. J., Lumma, W. C. \& Culberson, J. C. Development of nonnucleoside HIV reverse transcriptase inhibitors. Methods Enzymol. 275, 440-472 (1996).

8 Eliopoulos, G. M. et al. Invitro activity of a-86719.1, a novel 2-pyridinone antimicrobial agent. Antimicrob. Agents Chemother. 39, 850-853 (1995).

9 Erol, D. D. \& Yulug, N. Synthesis and antimicrobial investigation of thiazolinoalkyl4(1H)-pyridones. Eur. J. Med. Chem. 29, 893-897 (1994). 